\title{
, \\ Mobile Phone Radiation Deflects Brain Energy Homeostasis and Prompts Human Food Ingestion
}

\author{
Ewelina K. Wardzinski *, Kamila Jauch-Chara, Sarah Haars, Uwe H. Melchert, Harald G. Scholand-Engler ${ }^{\dagger}$ \\ and Kerstin M. Oltmanns
}

check for

updates

Citation: Wardzinski, E.K.;

Jauch-Chara, K.; Haars, S.; Melchert,

U.H.; Scholand-Engler, H.G.;

Oltmanns, K.M. Mobile Phone

Radiation Deflects Brain Energy

Homeostasis and Prompts Human

Food Ingestion. Nutrients 2022, 14,

339. https://doi.org/

10.3390/nu14020339

Academic Editor:

Stephane Sizonenko

Received: 11 November 2021

Accepted: 11 January 2022

Published: 14 January 2022

Publisher's Note: MDPI stays neutral with regard to jurisdictional claims in published maps and institutional affiliations.

Copyright: (C) 2022 by the authors. Licensee MDPI, Basel, Switzerland. This article is an open access article distributed under the terms and conditions of the Creative Commons Attribution (CC BY) license (https:// creativecommons.org/licenses/by/ $4.0 /)$.
Section of Psychoneurobiology, Center of Brain, Behavior and Metabolism, University of Luebeck, Ratzeburger Allee 160, 23538 Luebeck, Germany; kamila.jauch-chara@uksh.de (K.J.-C.); Sarah.Haars@medizin.uni-leipzig.de (S.H.); uwe.melchert@uni-luebeck.de (U.H.M.); kerstin.oltmanns@uni-luebeck.de (K.M.O.)

* Correspondence: e.wardzinski@uni-luebeck.de; Tel.: +49-451-3101-7534; Fax: +49-451-3101-7540

+ Deceased.

\begin{abstract}
Obesity and mobile phone usage have simultaneously spread worldwide. Radio frequencymodulated electromagnetic fields (RF-EMFs) emitted by mobile phones are largely absorbed by the head of the user, influence cerebral glucose metabolism, and modulate neuronal excitability. Body weight adjustment, in turn, is one of the main brain functions as food intake behavior and appetite perception underlie hypothalamic regulation. Against this background, we questioned if mobile phone radiation and food intake may be related. In a single-blind, sham-controlled, randomized crossover comparison, 15 normal-weight young men ( $23.47 \pm 0.68$ years) were exposed to $25 \mathrm{~min}$ of RF-EMFs emitted by two different mobile phone types vs. sham radiation under fasting conditions. Spontaneous food intake was assessed by an ad libitum standard buffet test and cerebral energy homeostasis was monitored by ${ }^{31}$ phosphorus-magnetic resonance spectroscopy measurements. Exposure to both mobile phones strikingly increased overall caloric intake by $22-27 \%$ compared with the sham condition. Differential analyses of macronutrient ingestion revealed that higher calorie consumption was mainly due to enhanced carbohydrate intake. Measurements of the cerebral energy content, i.e., adenosine triphosphate and phosphocreatine ratios to inorganic phosphate, displayed an increase upon mobile phone radiation. Our results identify RF-EMFs as a potential contributing factor to overeating, which underlies the obesity epidemic. Beyond that, the observed RF-EMFs-induced alterations of the brain energy homeostasis may put our data into a broader context because a balanced brain energy homeostasis is of fundamental importance for all brain functions. Potential disturbances by electromagnetic fields may therefore exert some generalized neurobiological effects, which are not yet foreseeable.
\end{abstract}

Keywords: mobile phone; radio frequency-modulated electromagnetic fields; brain; food intake; body weight

\section{Introduction}

Mobile phone usage is an essential part of day-to-day communication in modern society. Thirty years ago, the first mobile phone started its triumphant advance around the world, leading to more than six billion subscriptions [1]. During the same time period, rising body weight and obesity in the human population spread worldwide [2] and according to the Global Burden of Disease study obesity is one of the leading risk factors for death globally [3]. In fact, one in five children and adolescents worldwide are overweight [4], and specifically mobile phone usage is strongly associated with overweight in children [5]. Although at first sight a simultaneous increase in mobile phone usage and body weight gain appears to be pure coincidence, the idea that they may be related is not as far-fetched as it seems [6]. Mobile phone-emitted radiation, i.e., radio 
frequency-modulated electromagnetic fields (RF-EMFs), is absorbed to more than $80 \%$ by the head [7], enters the human brain [8-10], increases circumscribed glucose turnover underneath the antenna [11], elevates cortical excitability upon motor-evoked potentials [12], and influences electroencephalogram (EEG) monitoring [13,14], as well as cognitive-motor processes [14] in humans. In children and adolescents, a recent comprehensive study by Birks and co-workers demonstrated that mobile phone calls on $2 \mathrm{G}$ networks are the main determinants of brain dose [15] and respective radiation is absorbed more in the child's brain compared with adults [16,17]. Food intake regulation, in turn, is a function of hypothalamic and thereby central nervous appetite control [18]. Stimulation of the lateral hypothalamus drives feelings of appetite and initiates food intake while the ventromedial hypothalamus is responsible for satiety perception [19]. Daily RF-EMFs exposure for only $2 \mathrm{~h}$-beginning in prepubertal rats-increase food intake and body weight three weeks later in the adult rodent [20]. Moreover, prolonged exposition to RF-EMFs over a time period of 5-22 weeks has been shown to continue body weight gain and foster food intake in rodents [21-23]. Against this background, we experimentally tested if acute exposure to mobile phone radiation influences food consumption in humans. Because pulsed, as well as amplitude-modulated microwaves have been shown to affect brain energy homeostasis in rats [24] and, on the other hand, the cerebral energy status itself seems to play a key role in food intake [25] and body weight regulation [26,27], we assumed that potential effects of mobile phone exposure on food consumption may be mediated through their influence on cerebral energy homeostasis.

\section{Materials and Methods}

\subsection{Participants}

We tested 15 healthy young men aged 21 to 29 years (mean \pm s.e.m.: $23.47 \pm 0.68$ years) with a body mass index (BMI) of $20-25 \mathrm{~kg} / \mathrm{m}^{2}$ (range: $21.5-24.5 \mathrm{~kg} / \mathrm{m}^{2}$, mean BMI: $22.62 \pm 0.32 \mathrm{~kg} / \mathrm{m}^{2}$ ). All participants had a regular sleep-wake cycle for four weeks before testing. Exclusion criteria were acute or chronic internal, neurological, or psychiatric diseases, diabetes mellitus, obesity in 1st-degree family members, any kind of current medication, alcohol and/or drug abuse, smoking, shift work, and competitive sports. Before experimental testing, each volunteer gave written informed consent. Because sleep restriction enhances food consumption [28,29], participants were asked to go to bed no later than 11:00 p.m. before and during the experimental testing period. Additionally, participants were instructed to abstain from food and caffeine for $12 \mathrm{~h}$ before the experiments. No mobile phone use was allowed during the period of $12 \mathrm{~h}$ before the experiments, which was randomly controlled by test calls.

\subsection{Study Design}

The study was performed in a randomized, sham-controlled, single-blind, cross-over design. Each subject was tested on 3 experimental conditions for $25 \mathrm{~min}$ of exposure (mobile phone 1, mobile phone 2, and sham) spaced at least two weeks apart. On the days of experimental testing, participants reported to the Department of Neuroradiology at 6:30 a.m. after fasting for at least $12 \mathrm{~h}$. To ensure that all participants were fasting at the start of the measurements, blood glucose levels were determined. No participants showed statistically significant differences in their fasting blood glucose levels $(p=0.322)$. One cannula was inserted into an antecubital vein for blood sampling of glucose, insulin, and C-peptide as known factors influencing glucose metabolism and appetite regulation. Thereafter, a baseline ${ }^{31}$ phosporus magnetic resonance spectroscopy $\left({ }^{31} \mathrm{P}-\mathrm{MRS}\right)$ sequence was recorded. Subsequently, participants were exposed to $5 \mathrm{~min}$ of sham $/$ mobile phone radiation as described below. Immediately after this exposure, one ${ }^{31} \mathrm{P}-\mathrm{MRS}$ sequence was recorded to encompass potential direct effects of mobile phone exposure on brain energy metabolism. Thereafter, participants were exposed to additional $20 \mathrm{~min}$ of mobile phone or sham radiation. The duration of the exposure time was chosen regarding realistic and feasible aspects. Furthermore, studies are already available that provide guidance 
on appropriate stimulation times for anodal transcranial direct current stimulation in the context of high energy phosphates and food intake [30-32]. Subsequently, a series of 5 continuous ${ }^{31} \mathrm{P}$-MRS sequences was started. At 8:30 a.m., a standardized breakfast buffet $[25,33]$ was offered from which participants were allowed to eat ad libitum during the subsequent $40 \mathrm{~min}$. Participants were not informed about the actual purpose of the study to prevent them from putting a focus on food intake. Instead, they were told that the main intention of the study was to investigate the effects of mobile phone usage on cerebral energy metabolism. Thereby, participants were kept unaware of the hypothesized effects on food intake behavior and did not realize that their individual food consumption was quantified by weighing buffet components before and after the meal. To avoid overeating, participants were allowed to take with them any remaining food after final food weighing. Blood samples were obtained at baseline, at the end of the first mobile phone/sham phone exposure, at the end of the following spectroscopy recording, at the beginning and the end of the $20 \mathrm{~min}$ of mobile phone/sham phone exposure, at $10 \mathrm{~min}$ intervals during the 5 continuous spectroscopy sequences, and before and after the buffet test. Schematic illustration of the laboratory setting (Figure 1).

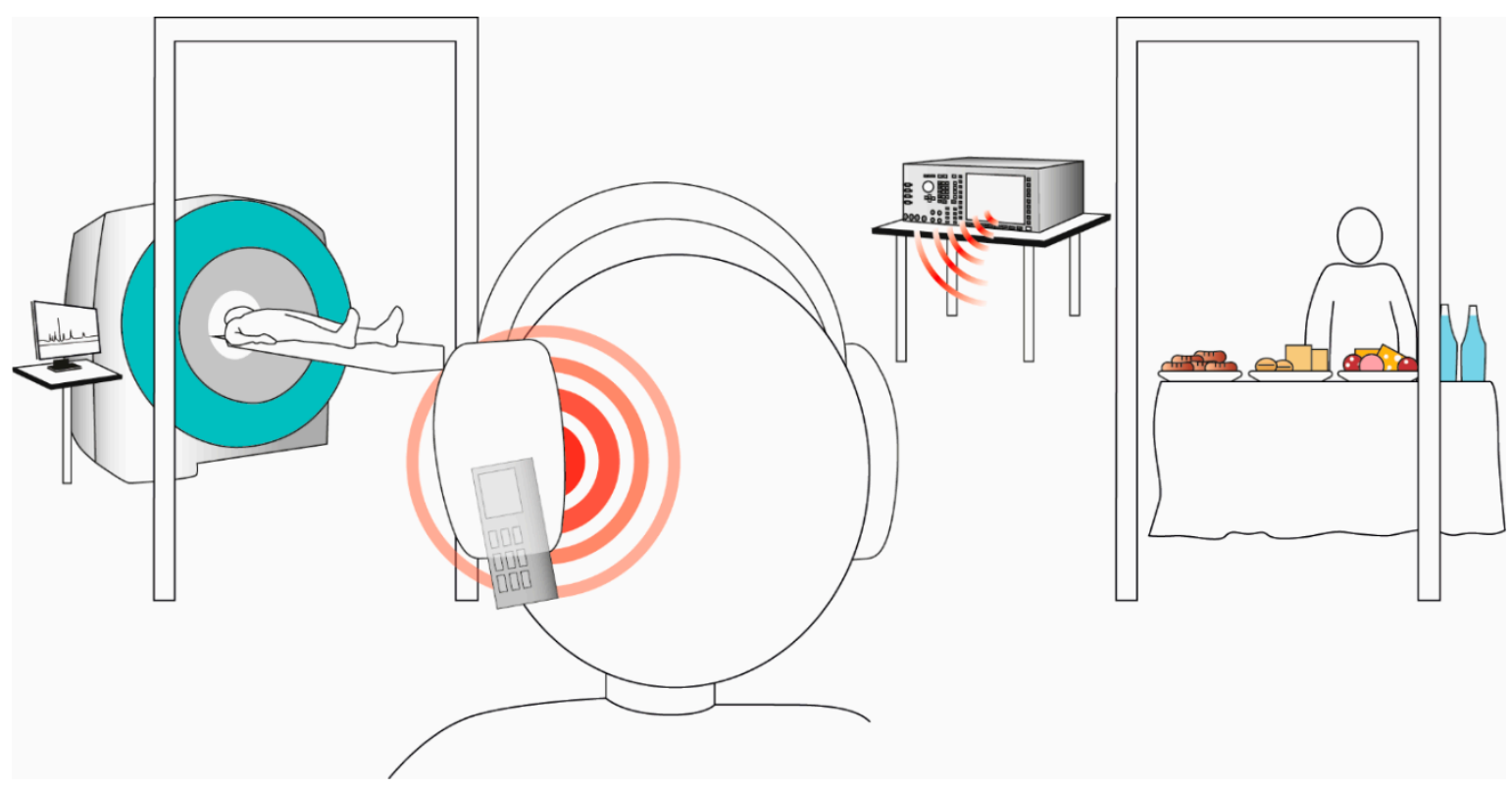

Figure 1. Schematic illustration of the laboratory setting. Individuals were exposed to two different continuously transmitting mobile phone types via a base station simulator working with maximal power vs. a deactivated phone as a sham condition. Mobile phones were installed in a compact headset without being visible to the participants to ensure that each subject exhibited the same distance between the mobile phone and the head. The antenna was located over the right temporal region. Participants were not given acoustic cues revealing the operation status of the mobile phones, i.e., they were unaware whether the phones were transmitting or not. Standardized buffet testing and MR-scanning procedure occurred in adjacent rooms.

\subsection{Mobile Phone Radiation Exposure}

In order to increase the overall validity of our data, we used two arbitrarily chosen commercially available mobile phones (phone 1: Motorola L2 (Motorola Mobility LLC), Libertyville, IL, USA and phone 2: Nokia 5800d-1 (Nokia Group, Helsinki, Finland)) in our experiments. Both transmitted in the Global System for Mobile Communications (GSM) standard $(900 \mathrm{MHz})$. Variances in RF-EMFs intensity due to environmental influence on phone reception quality were excluded by continuous transmission via a base station simulator (Universal Radio Communication Tester CMU 200, Rohde \& Schwarz GmbH \& Co. KG, Munich, Germany) working with maximal power [34,35]. Specific absorption 
rates (SAR) were $0.97 \mathrm{~W} / \mathrm{kg}$ for phone 2 and $1.33 \mathrm{~W} / \mathrm{kg}$ for phone 1 . Participants reclined comfortably in a horizontal position on a stretcher. Mobile phones were installed in a compact headset without being visible to the participants. This setting ensured that at each subject exhibited the same distance between mobile phone and head. The antenna was located over the right temporal region. In the sham condition, a deactivated phone was installed. Participants were not given acoustic cues revealing the operation status of the mobile phones, i.e., they were unaware whether the phones were transmitting or not.

\section{4. ${ }^{31}$ Phosphorus Magnetic Resonance Spectroscopy Measurements}

${ }^{31} \mathrm{P}-\mathrm{MRS}$ measurements of the motor cortex were conducted in a 3.0 Tesla MR scanner (Achieva 3T, Philips Medical Systems, Best, Amsterdam, The Netherlands) using a double-tuned ${ }^{1} \mathrm{H} /{ }^{31} \mathrm{P}$-headcoil (Advanced Imaging Research Inc., Cleveland, OH, USA). A repetition time of $4500 \mathrm{~ms}$ in conjunction with a three-dimensional chemical shift imaging (3D-CSI) sequence $(6 \times 5 \times 3$ voxel, $6 \mathrm{kHz}$ bandwidth, 1024 data points, 8:51 min measuring time) was used to reach sufficient relaxation of the phosphorus metabolites. For a better spectral resolution during excitation, ${ }^{1} \mathrm{H}$-decoupling and nuclear Overhauser effect (NOE) were applied [36] with broadband proton decoupling (10 rectangular RF pulses at proton resonance frequency of $10 \mathrm{~ms}$ duration and $10 \mathrm{~ms}$ delay between each other to generate a $90^{\circ}$ flip angle on the ${ }^{1} \mathrm{H}$ nuclei). During receiving, ${ }^{1} \mathrm{H}$-decoupling (wideband alternating-phase technique for zero-residual splitting: WALTZ-4) [37] was applied for transmitting on the ${ }^{1} \mathrm{H}$-resonance frequency using the 2 nd channel of the head coil. Magnetic Resonance User Interface (MRUI) was used for evaluation of the spectral data. Zerofilling to 4096 data points and apodizing with a $20 \mathrm{~Hz}$-Lorentzian-filter were applied. Peak positions and intensities were calculated by AMARES-algorithm [38]. Adenosine triphosphate (ATP) was determined as the sum of alpha-, beta-, and gamma-ATP. The ratios of phosphocreatine $(\mathrm{PCr})$ /inorganic phosphate $(\mathrm{Pi})$ and $\mathrm{ATP} / \mathrm{Pi}$ were evaluated as a common indicator of the intracellular energy status $[31,39,40]$. High-energy compounds are shown as single values at each time point. These values illustrate an arithmetic mean measured over all given voxels at a time point.

\subsection{Statistical Analysis}

Data are presented as mean values \pm standard error of mean (s.e.m.). Statistical analysis using Superior Performing Software Systems (SPSS, IBM, Armonk, NY, USA) was based on analysis of variance for repeated measurements (ANOVA), including the factors 'treatment' (phone 1 vs. phone 2 vs. sham) and 'time' (time points of data collection), as well as the interaction effect between these factors. The suitability of ANOVA was determined by Mauchly's sphericity test. In the case of violation of the sphericity conjecture, GreenhouseGeisser correction was applied. For pairwise comparisons, paired Student's $t$-test was used. A $p$-value less than 0.05 was considered significant.

\section{Results}

\subsection{Food Ingestion}

As hypothesized, we found that exposure to both transmitting mobile phones considerably increased total calorie consumption by $22 \%$ and $27 \%$ compared with the sham condition, respectively (phone 1: $1152.2 \pm 75.1$ vs. $941.6 \pm 85.2 \mathrm{kcal}, p=0.001$; phone 2: $1195.2 \pm 79.3$ vs. $941.6 \pm 85.2 \mathrm{kcal}, p=0.001$, Figure $2 \mathrm{a}$ ). Strikingly, we found this clear radiation-induced food intake boost in thirteen participants, i.e., in nearly all of our participants. Comparisons between both phone types did not reveal any significant differences in terms of their impact on total calorie consumption $(p=0.326)$. Because appetite regulation is intrinsically tied to glucose metabolism, we monitored concentrations of blood glucose, serum insulin, and C-peptide throughout the study. Results show that all measures remained unaffected by mobile phone exposure $(p>0.117$ for all analyses). Discrete analyses of the ingested macronutrients revealed that mobile phone radiation indeed enhanced carbohydrate $(p<0.001$ for both phones, Figure $2 \mathrm{~b}$ ) and protein (phone 1: $p=0.067$, 
phone 2: $p=0.014$, Figure 2c) intake. Fat consumption increased as a trend after phone 2 exposure, while there was no such effect in the phone 1 condition (phone 1: $p=0.119$, phone 2: $p=0.065$, Figure 2d). Basically, there was no difference in terms of macronutrient content of the ingested food between both phones $(p>0.251$ for all, Figure $2 b-d)$. These findings indicate that the exposure to both active mobile phones not only boosted calorie intake in general but specifically made participants consume more calories in the form of carbohydrates and-to a lesser extent-proteins, i.e., participants favored a special composition of food after mobile phone use.

a

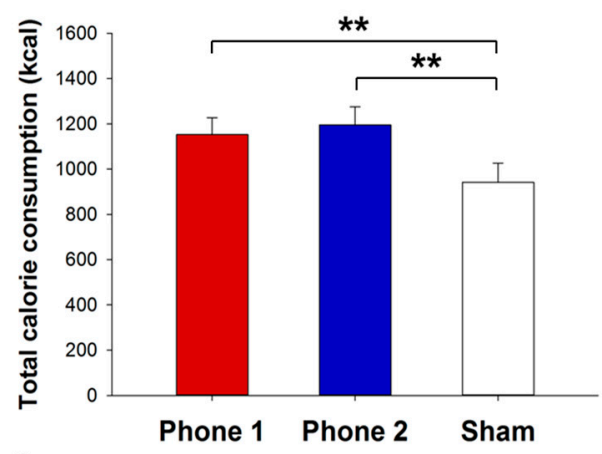

C

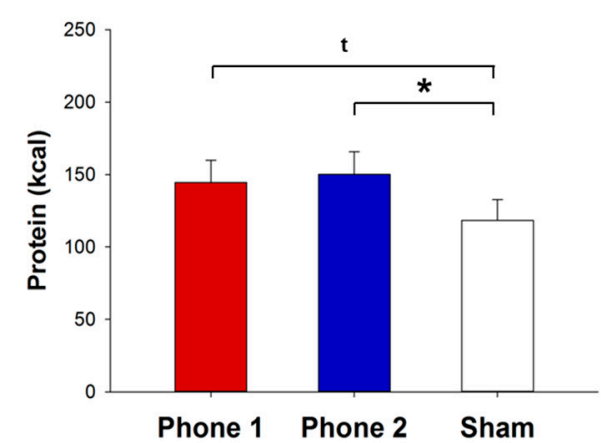

b

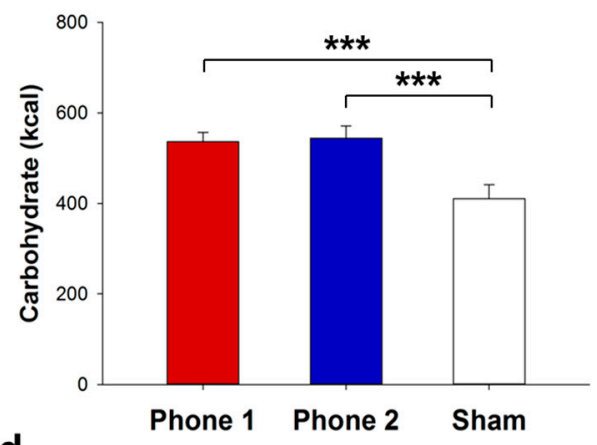

d

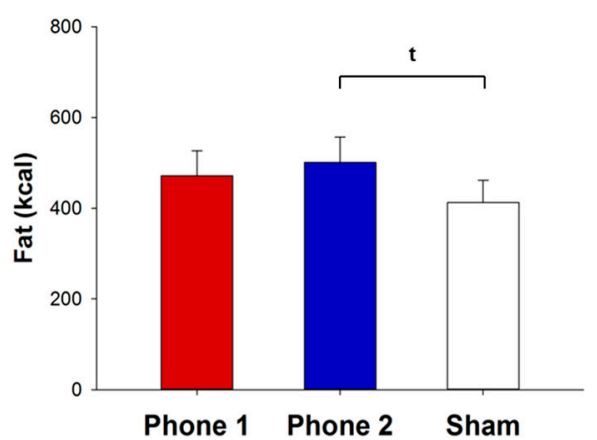

Figure 2. Calorie consumption after mobile phone exposure. Total calorie consumption (a), as well as ingested calorie content in the form of carbohydrates (b), proteins (c), and fat (d) from a standardized free-choice ad libitum buffet after $25 \mathrm{~min}$ of mobile phone (phone 1 (red bars) and phone 2 (blue bars) or sham (white bars)) exposure, respectively. Values are mean \pm s.e.m.; two-tailed Student's $t$-test; $n=15 ;{ }^{*} p<0.05,{ }^{* *} p<0.01,{ }^{* * *} p<0.001,{ }^{\mathrm{t}} p<0.1$.

\subsection{Cerebral High-Energy Phosphate Metabolism}

Results of ATP/Pi and PCr/Pi ratios show comparable values for all experimental conditions at baseline (all $p>0.429$ ), and after 5 min of mobile phone exposure (all $p>0.160$ ). After the extended radiation procedure for a further $20 \mathrm{~min}$, ATP/Pi levels were higher as a trend than after sham $(p=0.074$, Figure $3 a)$, an effect that was significant in terms of $\mathrm{PCr} / \mathrm{Pi}$ ratios $(p=0.038$, Figure $3 \mathrm{~b})$. Apparently, this was mainly due to differences at 50 and 55 min after radiation onset $(p<0.036$ and $p<0.006$, respectively, Figure $3 a, b)$. Comparison of mean post-exposure ATP/Pi values revealed significantly higher levels after RF-EMFs radiation compared with sham $(p=0.009$, Figure 3a, small insert). Differential analyses showed increased ATP/Pi levels by $3 \%$ after both phone $1(p=0.003)$ and phone 2 $(p=0.006)$ application than after sham, respectively (Figure $3 a$, small insert). These effects did not reach significance in terms of $\mathrm{PCr} / \mathrm{Pi}$ ratios ( $p>0.147$, Figure $3 b$, small insert). 


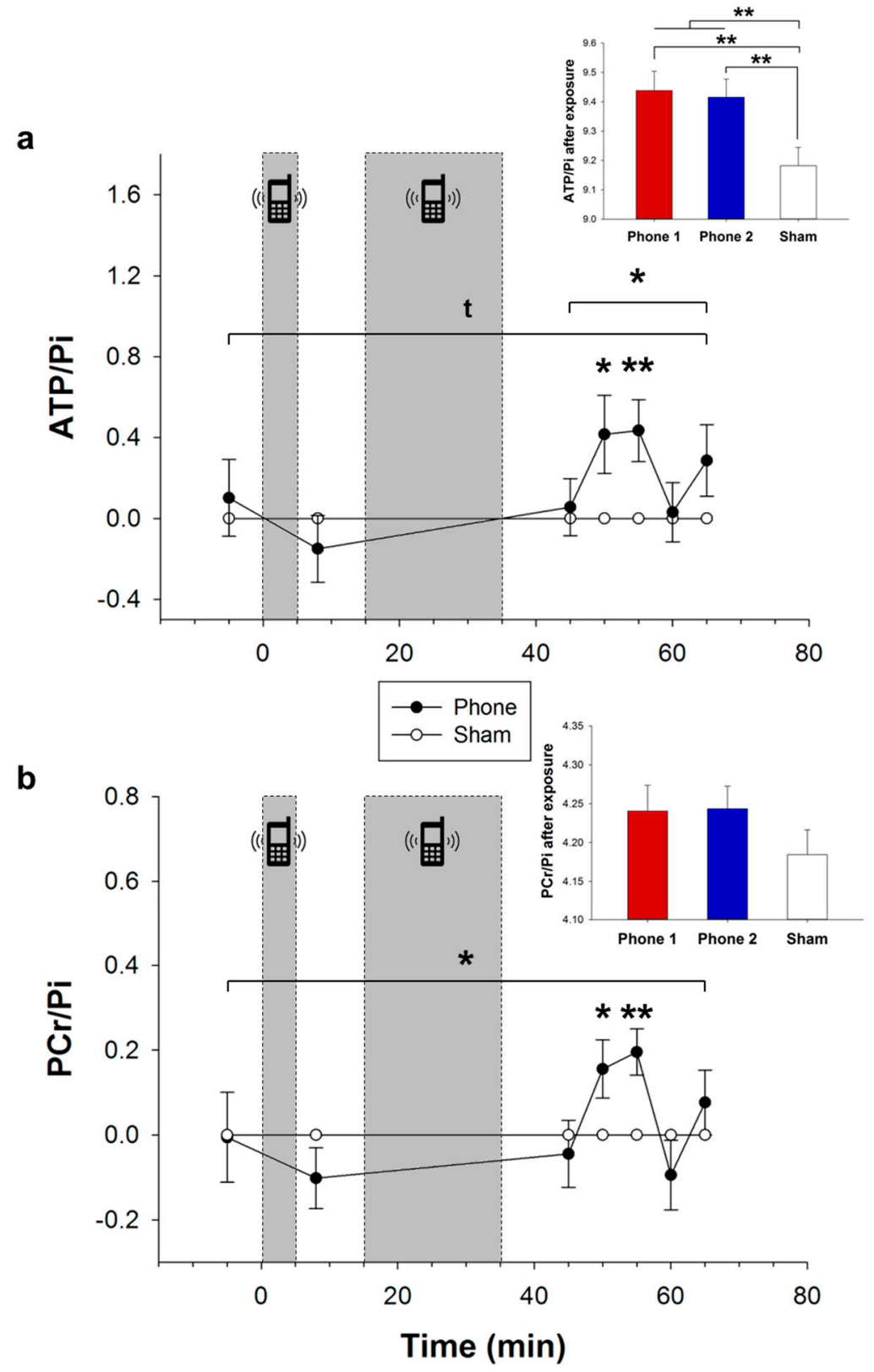

Figure 3. Effects of mobile phone exposure on neuroenergetic measures. Relative changes (mean values \pm s.e.m.) of cerebral $\mathrm{ATP} / \mathrm{Pi}(\mathbf{a})$ and $\mathrm{PCr} / \mathrm{Pi}$ ratios (b) after $5 \mathrm{~min}$ and a subsequent further $20 \mathrm{~min}$ of mobile phone radiation (both phones merged, black dots) in proportion to respective sham condition values (white dots). Grey areas mark the intervention period of mobile phone or sham exposure. Bar charts compare mean values \pm s.e.m. of phone 1 (red), phone 2 (blue), and sham (white) exposure, including all time points after intervention. ${ }^{*} p<0.05,{ }^{* *} p<0.01,{ }^{\mathrm{t}} p<0.1$.

\section{Discussion}

Our data show that mobile phone radiation by two different phone types leads to higher calorie consumption by $22 \%$ and $27 \%$, respectively. This effect was mainly based on an increased consumption of carbohydrates. This surprisingly unequivocal result is in line with scarce previous data from rodent studies, which examined food intake behavior upon RF-EMFs exposure. In fact, Tripathi and co-workers recently found an increased food intake after three weeks of a $2 \mathrm{~h}$ daily mobile phone exposure and consequent weight gain in rodents [20]. In another study, Lovely and co-workers observed an increased chow intake after RF-EMFs application of a comparable radiation intensity $(915 \mathrm{MHz})$ to our own experiment [41]. Pelletier and co-workers confirmed this result and demonstrated 
that continuous RF-EMFs exposure for five weeks causes an increased daytime intake of standard chow by $0.22 \mathrm{~g} / \mathrm{h}$ compared with a non-stimulated control group [23]. However, all data gained from rodents must be considered with caution when compared with our human experiments because RF-EMFs exposure generally irradiates the entire organism of small animals, leading to a considerable systemic heat supply which, in turn, increases the temperature by $0.5^{\circ} \mathrm{C}$ [42] and thereby the basal metabolic rate of the whole organism. Such systemic effect certainly influences food intake behavior per se. In contrast, our experimental setting of applying genuine mobile phone radiation for a realistic duration of 25 min within a circumscribed activity area close to the brain corresponds to realistic conditions and does not exert such thermal influence. Moreover, physical activity during the experiments may also be considered as a bias in animal studies. However, there are also human enquiries, which suggest a close relationship between RF-EMFs exposure and body mass index (BMI), as explored using anthropometric measurements and self-reported questionnaires in children [5] and from more than 4000 Finnish adolescent twins [43]. Due to this evidence, the relationship between RF-EMFs exposure and increased food consumption in our study deserves closer inspection. In addition to the increased food intake after mobile phone radiation, analyses of the distribution of ingested macronutrients revealed that exposure to both active mobile phones, not only boosted calorie intake in general, but specifically made participants consume more calories in the form of carbohydrates and-to a lesser extent-proteins. This corresponds with our previous work, which experimentally revealed that both the intranasal application of insulin and transcranial direct current stimulation suppress human calorie consumption specifically due to a lowered ingestion of carbohydrates [25,44] and proteins [25]. In conclusion, it is suggested that human carbohydrate intake is unconsciously susceptible to central nervous appetite signaling. In line, hypothalamic ghrelin level is increased, while glycolysis (hexokinase) is lower upon exposure to mobile phone radiation in rats [20], indicating a disturbed appetite regulation. Furthermore, current findings from Kim and co-workers demonstrate alterations in the postsynaptic structure and neurite outgrowth constraints on the hippocampal neurons of early postnatal mice [45]. The hypothalamus and hippocampus are crucially involved in the regulation of food intake and body weight [45-49], and both are affected by RF-EMFs radiation already in young rodent brains [20,45]. Moreover, in 5- and 10-year-old children, RF-EMFs exposure penetrates the brain far deeper than the mid-brain [50], reaching the hypothalamus amongst others [17]. An influence of RF-EMFs exposure on neuroenergetic functioning is particularly interesting as the hypothalamic glucose-sensing neurons respond to changes in cytosolic ATP levels, and carbohydrates, mostly in the form of glucose, play a crucial role as substrates of cerebral energy generation, i.e., brain adenosine triphosphate (ATP) synthesis. In line with this assumption, we found in our neuroenergetic measurements that RF-EMFs exposure affects cerebral high-energy phosphate homeostasis. In former studies, we found that obese individuals generally display reduced cerebral levels of the high-energy phosphates ATP and PCr $[39,40]$, the neuroenergetic status negatively correlates with food intake behavior [25], and the brain's high-energy phosphate content even predicts the amount of subsequently consumed calories [25]. However, with regard to the previously observed inverse relationship between neuroenergetic status, food consumption [25], and BMI [39,40], one would have rather expected a drop than an increase in high-energy phosphate content. On the other hand, the apparent enhancement in ATP synthesis rate upon RF-EMFs may have required some kind of compensational glucose replenishment to sustain the neuroenergetic homeostasis thereafter. This would be in line with findings of increasing brain glucose metabolism after $50 \mathrm{~min}$ of mobile phone exposure in healthy humans [11], and elevated hypothalamic gluconeogenesis in rats [20]. Therefore, it can be speculated in our study, that the boosted carbohydrate consumption after mobile phone exposure may have served to satisfy this elevated neuroenergetic glucose need after radiation exposure. We previously observed a similar effect during a stress intervention and after hypocaloric dieting in humans. Under both conditions, high-energy phosphates and food intake increased [27,33]. In fact, 60 min of mobile phone RF-EMFs exposure 
modulates the NADPH oxidase and induces a significant increase in mitochondrial membrane potential in human astrocytes [51]. These findings indicate that the use of mobile phones has an impact on the mitochondrial respiratory chain, which in turn is essential for ATP synthesis and is in line with very early data in rats showing that mitochondria utilize energy from an applied electric field to synthesize ATP [52]. However, the significance of the observed RF-EMFs-induced influence on the central nervous system may not be limited to food intake behavior. Alterations in brain energy homeostasis as observed here may exert a number of additional effects on brain function such as neurocognitive performance, mental health maintenance, or behavioral control $[53,54]$. This is particularly true since the influence of RF-EMFs is not restricted to single regions of the brain [15] but exerts some generalized neurobiological effects. Previous findings showed an association between mobile phone use and headache/migraine, concentration difficulties, fatigue, skin itches, and sleep disturbances in children and high school students $[55,56]$. We performed our experiments with young healthy adults but of course our findings lead to far-reaching considerations about the effects of mobile phone use in children as well. Early usage during childhood or even owning a mobile phone at young age leads to radiation exposure for a significantly longer period in their lives than all generations had experienced before $[57,58]$. On the one hand, children's brains absorb significantly higher radiation dosages emitted by mobile phones and RF-EMFs affect deeper brain structures (e.g., the hypothalamus) compared with adults $[15,17,50]$. On the other hand, childhood obesity is one of the most serious global public health challenges of the 21st century [59]. Against this background, our findings of increased food intake and deflected cerebral energy homeostasis upon mobile phone use give cause for concern, specifically in children and adolescents. However, it must be mentioned that some aspects of our study may limit the interpretation of our data. One may argue that, in our study, we tested rather antiquated types of mobile phones (which occurred on purpose to prevent harm to the producers' businesses), but a respective SAR between $0.97 \mathrm{~W} / \mathrm{kg}$ and $1.33 \mathrm{~W} / \mathrm{kg}$ is absolutely comparable to modern mobile phone types [60], and was in accordance with the guidelines from the International Commission on non-ionizing radiation protection [61]. It is well known that sleep restriction increases daily fat, protein, and carbohydrate intake, as well as the daily energy intake, in humans [62]. Furthermore, hypothalamic ATP levels decrease during sleep deprivation and strongly correlate with food intake [63] We, therefore, excluded participants with shift work and irregular sleep patterns and questioned them prior to testing about sleep disturbances during the preceding night. However, because we did not monitor sleep under controlled laboratory conditions, we cannot exclude the possibility that individual participants slept poorly or not at all before the measurements and did not communicate this with us. In addition, emotional stress can also affect food intake [64]. However, it must be considered that all participants were tested on three different days at least two weeks apart, so it is questionable as to whether such a transient variable can explain our significant results. By all means, in the context of the current obesity epidemic, our findings of mobile phone-induced enhancement in consumed calories by more than $22 \%$ in young men seems alarming, particularly since the underlying reasons of why people overeat despite the awareness of harmful consequences are still unknown. Furthermore, it remains to be clarified to what extent head-distant activities such as messaging also have an impact on human food intake. Environmental influence of RF-EMFs as also derived from electronic devices, such as wireless LAN, Bluetooth, radio, and television adding to a dysfunction of hypothalamic appetite regulation would offer a conceivable explanation here.

\section{Conclusions}

Our human study demonstrates that the RF-EMFs radiation emitted by mobile phones results in significantly increased food ingestion, particularly carbohydrate intake. Moreover, a deflected cerebral high-energy phosphate metabolism, which is closely related to food intake and body weight, was found after mobile phone use. Therefore, our results identify RF-EMFs as a potential contributing factor to overeating in humans, which underlies 
the worldwide obesity epidemic. Beyond this, RF-EMF-induced alterations of the brain energy homeostasis, as observed here, may put our data into a broader context because a balanced central nervous energy homeostasis is of fundamental importance, not only for the regulation of food intake and body weight, but also for all brain functions. Therefore, with good cause, the high priority of this research field was already emphasized a long time ago by the WHO Research Agenda for Radiofrequency Fields [65]. Perhaps our data could serve as first step towards deeper insight into this issue and open a new perspective in neurobiological and obesity research.

Author Contributions: E.K.W.: data curation, visualization, validation, writing-original draft. K.J.-C.: conceptualization, methodology, investigation, project administration, formal analyses, visualization. S.H.: investigation, data curation, methodology, visualization. U.H.M. and H.G.S.-E.: data curation, investigation, methodology, resources, software, visualization. K.M.O.: conceptualization, funding acquisition, methodology, project administration, resources, supervision, validation, writing - original draft, writing - review, editing. All authors have read and agreed to the published version of the manuscript.

Funding: The study was funded by the German Research Foundation (Deutsche Forschungsgemeinschaft, Grant No. SFB-TRR 134).

Institutional Review Board Statement: The study was conducted according to the guidelines of the Declaration of Helsinki, and approved by the Ethics Committee of the University of Luebeck (protocol code 11-152 and date of approval 21 December 2011).

Informed Consent Statement: Informed consent was obtained from all participants involved in the study.

Data Availability Statement: Data are contained within the article and could be presented on request.

Acknowledgments: To our regret, Harald G. Scholand-Engler passed away before publication.

Conflicts of Interest: The authors declare no conflict of interest.

\section{References}

1. Statista, Number of Smartphone Users from 2016 to 2021. Available online: https:/ / www.statista.com/statistics/330695/numberof-smartphone-users-worldwide/ (accessed on 8 August 2021).

2. Swinburn, B.A.; Sacks, G.; Hall, K.D.; McPherson, K.; Finegood, D.T.; Moodie, M.L.; Gortmaker, S.L. The global obesity pandemic: Shaped by global drivers and local environments. Lancet 2011, 37, 804-814. [CrossRef]

3. Collaborators, G.B.D.R.F. Global burden of 87 risk factors in 204 countries and territories, 1990-2019: A systematic analysis for the Global Burden of disease study 2019. Lancet 2020, 396, 1223-1249.

4. WHO. Fact Sheet-Obesity and Overweight. Updated 2020. Available online: https://www.who.int/en/news-room/fact-sheets/ detail/obesity-and-overweight (accessed on 6 June 2020).

5. Wada, K.; Yamakawa, M.; Konishi, K.; Goto, Y.; Mizuta, F.; Koda, S.; Uji, T.; Tamura, T.; Nakamura, K.; Tsuji, M.; et al. Associations of cell phone use and screen viewing with overweight in children. Child Obes. 2019, 15, 417-425. [CrossRef]

6. Kim, K.H.; Kabir, E.; Jahan, S.A. The use of cell phone and insight into its potential human health impacts. Environ. Monit. Assess. 2016, 188, 221. [CrossRef]

7. Fernandez, C.; de Salles, A.A.; Sears, M.E.; Morris, R.D.; Davis, D.L. Absorption of wireless radiation in the child versus adult brain and eye from cell phone conversation or virtual reality. Environ. Res. 2018, 167, 694-699. [CrossRef]

8. Cardis, E.; Deltour, I.; Mann, S.; Moissonnier, M.; Taki, M.; Varsier, N.; Wake, K.; Wiart, J. Distribution of RF energy emitted by mobile phones in anatomical structures of the brain. Phys. Med. Biol. 2008, 53, 2771-2783. [CrossRef]

9. Cardis, E.; Varsier, N.; Bowman, J.D.; Deltour, I.; Figuerola, J.; Mann, S.; Moissonnier, M.; Taki, M.; Vecchia, P.; Villegas, R.; et al. Estimation of RF energy absorbed in the brain from mobile phones in the Interphone Study. Occup. Environ. Med. 2011, 68, 686-693. [CrossRef]

10. Gultekin, D.H.; Moeller, L. NMR imaging of cell phone radiation absorption in brain tissue. Proc. Natl. Acad. Sci. USA 2013, 110, 58-63. [CrossRef] [PubMed]

11. Volkow, N.D.; Tomasi, D.; Wang, G.J.; Vaska, P.; Fowler, J.S.; Telang, F.; Alexoff, D.; Logan, J.; Wong, C. Effects of cell phone radiofrequency signal exposure on brain glucose metabolism. JAMA 2011, 305, 808-813. [CrossRef] [PubMed]

12. Ferreri, F.; Curcio, G.; Pasqualetti, P.; De Gennaro, L.; Fini, R.; Rossini, P.M. Mobile phone emissions and human brain excitability. Ann. Neurol. 2006, 60, 188-196. [CrossRef] [PubMed]

13. Roggeveen, S.; van Os, J.; Viechtbauer, W.; Lousberg, R. EEG changes due to experimentally induced 3G mobile phone radiation. PLOS ONE 2015, 10, e0129496. 
14. Vecchio, F.; Buffo, P.; Sergio, S.; Iacoviello, D.; Rossini, P.M.; Babiloni, C. Mobile phone emission modulates event-related desynchronization of alpha rhythms and cognitive-motor performance in healthy humans. Clin. Neurophysiol. 2012, 123, 121-128. [CrossRef]

15. Birks, L.E.; van Wel, L.; Liorni, I.; Pierotti, L.; Guxens, M.; Huss, A.; Foerster, M.; Capstick, M.; Eeftens, M.; El Marroun, H.; et al. Radiofrequency electromagnetic fields from mobile communication: Description of modeled dose in brain regions and the body in European children and adolescents. Environ. Res. 2021, 193, 110505. [CrossRef] [PubMed]

16. Wiart, J.; Hadjem, A.; Gadi, N.; Bloch, I.; Wong, M.F.; Pradier, A.; Lautru, D.; Hanna, V.F.; Dale, C. Modeling of RF head exposure in children. Bioelectromagnetics 2005, 26, S19-S30. [CrossRef]

17. Christ, A.; Gosselin, M.-C.; Christopoulou, M.; Kühn, S.; Kuster, N. Age-dependent tissue-specific exposure of cell phone users. Phys. Med. Biol. 2010, 55, 1767-1783. [CrossRef] [PubMed]

18. Schwartz, M.W.; Porte, D., Jr. Diabetes, obesity, and the brain. Science 2005, 307, 375-379. [CrossRef] [PubMed]

19. Lam, T.K. Neuronal regulation of homeostasis by nutrient sensing. Nat. Med. 2010, 16, 392-395. [CrossRef]

20. Tripathi, R.; Banerjee, S.K.; Nirala, J.P.; Mathur, R. Simultaneous exposure to electromagnetic field from mobile phone and unimpeded fructose drinking during pre-peri-and post-pubertal stages perturbs the hypothalamic and hepatic regulation of energy homeostasis by early adulthood: Experimental evidence. Environ. Sci. Pollut. Res. Int. 2021, 1-14. [CrossRef]

21. Sommer, A.M.; Streckert, J.; Bitz, A.K.; Hansen, V.W.; Lerchl, A. No effects of GSM-modulated 900 MHz electromagnetic fields on survival rate and spontaneous development of lymphoma in female AKR/J mice. BMC Cancer 2004, 4, 77. [CrossRef]

22. Lerchl, A.; Kruger, H.; Niehaus, M.; Streckert, J.R.; Bitz, A.K.; Hansen, V. Effects of mobile phone electromagnetic fields at nonthermal SAR values on melatonin and body weight of Djungarian hamsters (Phodopus sungorus). J. Pineal. Res. 2008, 44, 267-672. [CrossRef]

23. Pelletier, A.; Delanaud, S.; Decima, P.; Thuroczy, G.; de Seze, R.; Cerri, M.; Bach, V.; Libert, J.P.; Loos, N. Effects of chronic exposure to radiofrequency electromagnetic fields on energy balance in developing rats. Environ. Sci. Pollut. Res. Int. 2013, 20, 2735-2746. [CrossRef]

24. Sanders, A.P.; Joines, W.T.; Allis, J.W. Effects of continuous-wave, pulsed, and sinusoidal-amplitude-modulated microwaves on brain energy metabolism. Bioelectromagnetics 1985, 6, 89-97. [CrossRef] [PubMed]

25. Jauch-Chara, K.; Friedrich, A.; Rezmer, M.; Melchert, U.H.; Scholand-Engler, H.G.; Hallschmid, M.; Oltmanns, K.M. Intranasal insulin suppresses food intake via enhancement of brain energy levels in humans. Diabetes 2012, 61, 2261-2268. [CrossRef]

26. Jauch-Chara, K.; Oltmanns, K.M. Obesity-A neuropsychological disease? Systematic review and neuropsychological model. Prog. Neurobiol. 2014, 114, 84-101. [CrossRef]

27. Wardzinski, E.K.; Hyzy, C.; Duysen, K.; Melchert, U.H.; Jauch-Chara, K.; Oltmanns, K.M. Hypocaloric dieting unsettles the neuroenergetic homeostasis in humans. Nutrients 2021, 13, 3433. [CrossRef] [PubMed]

28. Spaeth, A.M.; Dinges, D.F.; Goel, N. Effects of experimental sleep restriction on weight gain, caloric intake, and meal timing in healthy adults. Sleep 2013, 36, 981-990. [CrossRef] [PubMed]

29. Kracht, C.L.; Chaput, J.P.; Martin, C.K.; Champagne, C.M.; Katzmarzyk, P.T.; Staiano, A.E. Associations of sleep with food cravings, diet, and obesity in adolescence. Nutrients 2019, 11, 2899. [CrossRef]

30. Kistenmacher, A.; Manneck, S.; Wardzinski, E.K.; Martens, J.C.; Gohla, G.; Melchert, U.H.; Jauch-Chara, K.; Oltmanns, K.M. Persistent blood glucose reduction upon repeated transcranial electric stimulation in men. Brain Stimul. 2017, 10, 780-786. [CrossRef]

31. Wardzinski, E.K.; Friedrichsen, L.; Dannenberger, S.; Kistenmacher, A.; Melchert, U.H.; Jauch-Chara, K.; Oltmanns, K.M. Double transcranial direct current stimulation of the brain increases cerebral energy levels and systemic glucose tolerance in men. $J$. Neuroendocrinol. 2019, 31, e12688. [CrossRef]

32. Binkofski, F.; Loebig, M.; Jauch-Chara, K.; Bergmann, S.; Melchert, U.H.; Scholand-Engler, H.G.; Schweiger, U.; Pellerin, L.; Oltmanns, K.M. Brain energy consumption induced by electrical stimulation promotes systemic glucose uptake. Biol. Psychiatry 2011, 70, 690-695. [CrossRef]

33. Kistenmacher, A.; Goetsch, J.; Ullmann, D.; Wardzinski, E.K.; Melchert, U.H.; Jauch-Chara, K.; Oltmanns, K.M. Psychosocial stress promotes food intake and enhances the neuroenergetic level in men. Stress 2018, 21, 538-547. [CrossRef]

34. Cassioli, D.; Durantini, A. Measurements, modeling and simulations of the UWB propagation channel based on direct-sequence channel sounding. Wirel. Commun. Mob. Comput. 2005, 5, 513-523. [CrossRef]

35. Dudoyer, S.; Deniau, V.; Adriano, R.; Ben Slimen, M.N.; Rioult, J.; Meyniel, B.; Berbineau, M. Study of the susceptibility of the GSM-R communications face to the electromagnetic interferences of the rail environment. IEEE Trans. Electromagn. Compat. 2012, 54, 667-676. [CrossRef]

36. Bachert-Baumann, P.; Ermark, F.; Zabel, H.J.; Sauter, R.; Semmler, W.; Lorenz, W.J. In vivo nuclear Overhauser effect in 31P-(1H) double-resonance experiments in a 1.5-T whole-body MR system. Magn. Reson. Med. 1990, 15, 165-172. [CrossRef]

37. Barker, P.B.; Golay, X.; Artemov, D.; Ouwerkerk, R.; Smith, M.A.; Shaka, A.J. Broadband proton decoupling for in vivo brain spectroscopy in humans. Magn. Reson. Med. 2001, 45, 226-232. [CrossRef]

38. Vanhamme, L.; van den Boogaart, A.; Van Huffel, S. Improved method for accurate and efficient quantification of MRS data with use of prior knowledge. J. Magn. Reson. 1997, 129, 35-43. [CrossRef] 
39. Schmoller, A.; Hass, T.; Strugovshchikova, O.; Melchert, U.H.; Scholand-Engler, H.G.; Peters, A.; Schweiger, U.; Hohagen, F.; Oltmanns, K.M. Evidence for a relationship between body mass and energy metabolism in the human brain. J. Cereb. Blood Flow Metab. 2010, 30, 1403-1410. [CrossRef]

40. Wardzinski, E.K.; Kistenmacher, A.; Melchert, U.H.; Jauch-Chara, K.; Oltmanns, K.M. Impaired brain energy gain upon a glucose load in obesity. Metabolism 2018, 85, 90-96. [CrossRef] [PubMed]

41. Lovely, R.H.; Mizumori, S.J.Y.; Johnson, R.B.; Guy, A.W. Subtle consequences of exposure to weak microwave fields: Are there nonthermal effects? A2-ADAIR, ELEANOR R. In Microwaves and Thermoregulation; Academic Press: San Diego, CA, USA, 1983; pp. 401-429.

42. Taberski, K.; Klose, M.; Grote, K.; El Ouardi, A.; Streckert, J.; Hansen, V.W.; Lerchl, A. Noninvasive assessment of metabolic effects of exposure to $900 \mathrm{MHz}$ electromagnetic fields on Djungarian Hamsters (Phodopus sungorus). Radiat. Res. 2014, 181, 617-622. [CrossRef]

43. Lajunen, H.R.; Keski-Rahkonen, A.; Pulkkinen, L.; Rose, R.J.; Rissanen, A.; Kaprio, J. Are computer and cell phone use associated with body mass index and overweight? A population study among twin adolescents. BMC Public Health 2007, 7, 24. [CrossRef]

44. Jauch-Chara, K.; Kistenmacher, A.; Herzog, N.; Schwarz, M.; Schweiger, U.; Oltmanns, K.M. Repetitive electric brain stimulation reduces food intake in humans. Am. J. Clin. Nutr. 2014, 100, 1003-1009. [CrossRef]

45. Kim, J.H.; Chung, K.H.; Hwang, Y.R.; Park, H.R.; Kim, H.J.; Kim, H.-G.; Kim, H.R. Exposure to RF-EMF alters postsynaptic structure and hinders neurite outgrowth in developing hippocampal neurons of early postnatal mice. Int. J. Mol. Sci. 2021, 22, 5340. [CrossRef] [PubMed]

46. Stevenson, R.J.; Francis, H.M. The hippocampus and the regulation of human food intake. Psychol. Bull. 2017, 143, 1011-1032 [CrossRef]

47. Pocai, A.; Lam, T.K.; Gutierrez-Juarez, R.; Obici, S.; Schwartz, G.J.; Bryan, J.; Aguilar-Bryan, L.; Rossetti, L. Hypothalamic K(ATP) channels control hepatic glucose production. Nature 2005, 434, 1026-1031. [CrossRef]

48. Schwartz, M.W.; Woods, S.C.; Porte, D.; Seeley, R.J.; Baskin, D.G. Central nervous system control of food intake. Nature 2000, 404, 661-671. [CrossRef] [PubMed]

49. Yang, S.; Yang, H.; Chang, R.; Yin, P.; Yang, Y.; Yang, W.; Huang, S.; Gaertig, M.A.; Li, S.; Li, X.-J. MANF regulates hypothalamic control of food intake and body weight. Nat. Commun. 2017, 8, 579. [CrossRef]

50. Gandhi, O.P.; Lazzi, G.; Furse, C.M. Electromagnetic absorption in the human head and neck for mobile telephones at 835 and 1900 MHz. IEEE Trans. Microw. Theory Tech. 1996, 44, 1884-1897. [CrossRef]

51. Tsoy, A.; Saliev, T.; Abzhanova, E.; Turgambayeva, A.; Kaiyrlykyzy, A.; Akishev, M.; Saparbayev, S.; Umbayev, B.; Askarova, S. The effects of mobile phone radiofrequency electromagnetic fields on beta-amyloid-induced oxidative stress in human and rat primary astrocytes. Neuroscience 2019, 408, 46-57. [CrossRef]

52. Teissie, J.; Knox, B.E.; Tsong, T.Y.; Wehrle, J. Synthesis of adenosine triphosphate in respiration-inhibited submitochondrial particles induced by microsecond electric pulses. Proc. Natl. Acad. Sci. USA 1981, 78, 7473-7477. [CrossRef] [PubMed]

53. Sharma, A.; Sharma, S.; Shrivastava, S.; Singhal, P.K.; Shukla, S. Mobile phone induced cognitive and neurochemical consequences. J. Chem. Neuroanat. 2019, 102, 101684. [CrossRef]

54. Singh, K.V.; Gautam, R.; Meena, R.; Nirala, J.P.; Jha, S.K.; Rajamani, P. Effect of mobile phone radiation on oxidative stress, inflammatory response, and contextual fear memory in Wistar rat. Environ. Sci. Pollut. Res. Int. 2020, 27, 19340-19351. [CrossRef]

55. Durusoy, R.; Hassoy, H.; Ozkurt, A.; Karababa, A.O. Mobile phone use, school electromagnetic field levels and related symptoms: A cross-sectional survey among 2150 high school students in Izmir. Environ. Health 2017, 16, 51. [CrossRef] [PubMed]

56. Chiu, C.T.; Chang, Y.H.; Chen, C.C.; Ko, M.C.; Li, C.Y. Mobile phone use and health symptoms in children. J. Formos. Med. Assoc. 2015, 114, 598-604. [CrossRef] [PubMed]

57. Rideout, V. The Common Sense Census: Media Use by Kids Age Zero to Eight; Common Sense Media: San Francisco, CA, USA, 2017; pp. 263-283.

58. Kabali, H.K.; Irigoyen, M.M.; Nunez-Davis, R.; Budacki, J.G.; Mohanty, S.H.; Leister, K.P.; Bonner, R.L., Jr. Exposure and use of mobile media devices by young children. Pediatrics 2015, 136, 1044-1050. [CrossRef]

59. Reilly, J.J.; El-Hamdouchi, A.; Diouf, A.; Monyeki, A.; Somda, S.A. Determining the worldwide prevalence of obesity. Lancet 2018, 391, 1773-1774. [CrossRef]

60. Mondal, S.P.; Padmini, T.N. Specific absorption rate (SAR), ways to find in mobile devices, its measurement and side effects on human. In Proceedings of the 2019 International Conference on Vision Towards Emerging Trends in Communication and Networking (ViTECoN), Vellore, India, 30-31 March 2019; pp. 1-4.

61. International Commission on Non-Ionizing Radiation Protection. Guidelines for limiting exposure to electromagnetic fields (100 kHz to $300 \mathrm{GHz})$. Health Phys. 2020, 118, 483-524. [CrossRef]

62. Fenton, S.; Burrows, T.L.; Skinner, J.A.; Duncan, M.J. The influence of sleep health on dietary intake: A systematic review and meta-analysis of intervention studies. J. Hum. Nutr. Diet. 2021, 34, 273-285. [CrossRef]

63. Dworak, M.; Kim, T.; McCarley, R.W.; Basheer, R. Sleep, brain energy levels, and food intake: Relationship between hypothalamic ATP concentrations, food intake, and body weight during sleep-wake and sleep deprivation in rats. Somnologie 2011, 15, 111-117. [CrossRef] 
64. López-Cepero, A.; O’Neill, J.; Tamez, M.; Falcón, L.M.; Tucker, K.L.; Rodríguez-Orengo, J.F.; Mattei, J. Associations between perceived stress and dietary intake in adults in Puerto Rico. J. Acad. Nutr. Diet. 2021, 121, 762-769. [CrossRef]

65. van Deventer, E.; van Rongen, E.; Saunders, R. WHO research agenda for radiofrequency fields. Bioelectromagnetics 2011, 32, 417-421. [CrossRef] [PubMed] 